\title{
The Necessity for Central Clearing Houses for Butchers' Meat,
} by E. W. Rees Jones, M.D., D.P.H., Medical Officer of Health, Blackpool (MEMBER).

THE object of this brief paper is to draw the attention of this section 1 of the Congress to one of the difficulties met with by active public health authorities, and to elicit from delegates views as to the feasibility of the suggestions of the writer. The two main causes of the situation, which we all agree requires amending, are: (1) The inefficiency or absence of meat inspection in rural districts, and (2) the woeful absence up and down the country of public abattoirs. The amount of butchers' meat efficiently inspected before it passes into the consumers' hands is very small in comparison with the total amount consumed. The uninspected meat passes through one of two channels: it is either imported into the town from adjacent farms (and often the animal is killed because it is ailing), or it is slaughtered in other than public abattoirs, and a remedy which I suggest is the establishment in towns (in which, of course, the majority of meat consumers reside) of "clearing houses," where imported meat may be inspected and stamped. A system such as this is very desirable in the interests of the public, and also of the butchers. The latter body of men are liable to have foisted upon them unsound meat which may have escaped their observation, or the unsoundness of which they may have been unable to detect, and thus may render themselves liable to heary penalties for offences of which they may be innocent. The trading instinct being so strong in us all, this risk is increased by the favourable prices at which the meat is frequently offered to the middleman butcher.

It is not the intention of the writer to elaborate any scheme, or to consider the details of any working arrangements. A considerable number of difficulties would have to be overcome before even a modified scheme could be inangurated, and some additional expense would have to be met. It should, in the first instance, be voluntary, but it is hoped that this would in reality amount to a compulsory scheme, as preference would be given by purchasing butchers to meat which had passed throngh the clearing house. Also it must be borne in mind that carcases which are even extensively diseased can be so manipulated and cut up that examination of individual joints would not reveal the presence of disease. Cases such as these would be difficult to deal with, but could only be met, in the first instance, by a refusal on the part of the inspector 
in charge of the clearing house to stamp individual joints. In this connection it would be well to warn butchers once more against accepting dressed carcases which have been stripped, or which are not accompanied by the viscera.

DR. T. W. N. BARLOW (Wallasey) emphasised the importance of this subject. Meat inspection was in a most unsatisfactory condition. The standard depended entirely on the individual idiosyncracy of the observer where there was inspection; but in the rural districts and a large number of urban districts there was no inspection at all. There should be power to detain carcases in slaughterhouses until inspected; after inspection, if passed by the inspector, they should be stamped. The suggestion of clearing houses where all meat arriving into a town must be deposited and inspected before distribution was an admirable one.

Mr. J. C. Coleman (Swindon) said the two main objections to the previous inefficiency of inspection noted undoubtedly existed; in fact, it was only a very small percentage of the meat supply which received any inspection at all. $\mathrm{He}$ was most anxious to impress upon the conference and the public the lack of knowledge they and their officials possessed of the true state of affairs; in other words, they little dreamt of the terribly diseased carcases which found their way into the butchers' shops, many of which had passed inspection, owing to the absence in all probability of the viscera which should remain attached until after the carcase was inspected. Meat inspection should be uniform the country over. The number of apparently tuberculous emaciated cattle which had been killed since May, 1913, would startle you; many of these would somehow have eluded inspection, and, under ordinary circumstanees, have been sold for human food. The removal of diseased organs made it practically impossible to detect the presence of disease in many cases.

DB. DaLEY (Bootle) said he happened to be a certifying officer for the exportation of meat food products to the United States of America and the Phillipine Islands. All meat which was sent from England to those places had to be certified to be sound and to have come from healthy animals, otherwise it would not be received there. The animals were examined by a veterinary surgeon at the place where they were slaughtered, and the carcases branded in a special manner; the preparation of hams from the curcases was supervised as was the packing of the finished hams into cases, which were sealed and labelled All that was done for commercial reasons, that their meat should be received in foreign countries. Surely it was not impossible to do the same for meat to be consumed by our own kith and kin. 